\title{
reviews
}

columns

\section{Think Good - Feel Good. A Cognitive Behaviour Therapy Workbook for Children and Young People}

\section{Stallard, P.}

Chichester: John Wiley \& Sons, 2002, f24.95 pb, $186 \mathrm{pp}$.

ISBN: 0-470-84290-3

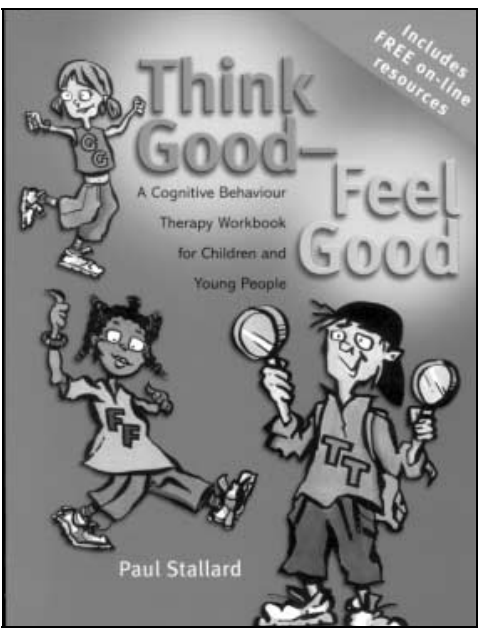

This comprehensive text covers the different aspects of cognitive-behavioural approaches for children and young people. The extent of knowledge required to claim a grasp of the art of cognitivebehavioural therapy (CBT) is apparent within this book and information is presented at the requisite depth for its target group. The book addresses theoretical aspects of CBT in a methodical format, and so acts as an aide memoire for those with some formal instruction in the science. The introductory section on CBT with children and young people usefully visits the evidence base for its strengths and weaknesses in this age group. It appropriately considers developmental perspective issues that impact on the success of this technique.

Whereas Think Good - Feel Good was not intended to be delivered systematically as a package in a standardized 10 session course, I have used it very much in that fashion with satisfaction and success, finding that the structure appealed to this age group.

It is superbly complemented by ageappropriate graphics that serve to enhance its audience appeal and make it less like another academic struggle. In addition, I particularly liked the overall dimensions, font size and page design making the book format easy to use as a template for sessions. Another strength of this book lies in the free availability of text and workbook resources through the website, which has been well received by its users. I have enjoyed using the book and experienced success with it having enriched my own clinical skill battery.

David McNamara Consultant Child and Adolescent Psychiatrist, Oxleas NHS Trust, 2 Newman Road, Bromley BR1 1RJ

\section{Working with Interpreters in Mental Health}

Tribe, R. \& Raval, H. London: Brunner-Routledge, 2002, f16.99 pb, $270 \mathrm{pp}$.

ISBN: 0-415-18878-2

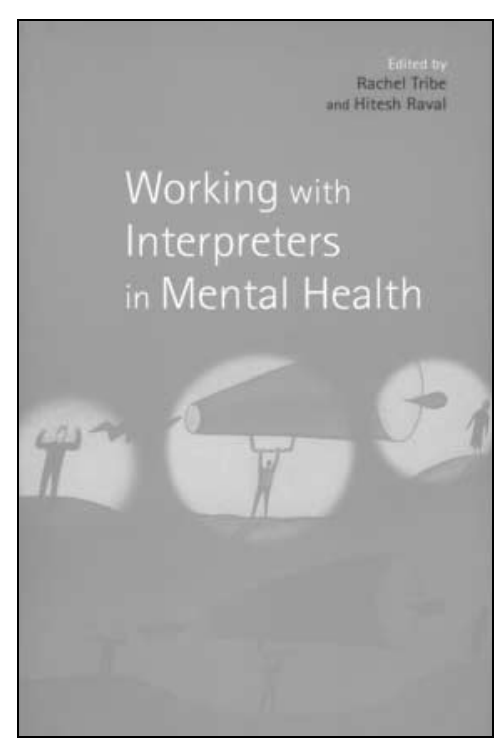

Occasionally, all psychiatrists need the help of an interpreter. For many, working with interpreters is a regular, and increasingly frequent, aspect of routine work. An ability to work competently with interpreters is now a requirement of the MRCPsych basic specialist curriculum. When reading this book, I conducted a small, unrepresentative and biased survey of mental health staff and medical students. The results suggested that although communication skills are now widely taught, specific training on how to work with interpreters is still a rarity. This is an extraordinary omission. Communicating effectively is the essence of what we all do, and is never more vital than when trying to help people from different cultures.

This book provides the basics on how to work effectively with an interpreter, but also much more. Chapters written by interpreters themselves help to highlight the fragility of their profession, the difficulties they face in day-to-day work and their strong feelings of being undervalued. Other chapters focus on therapeutic work with interpreters, and theoretical models that underpin much of the work. There are chapters devoted to the specific problems of refugees. Throughout the book, there are case vignettes and descriptions of individual services, which helps to keep the text lively and interesting.

Sadly, some of what is advocated is difficult, if not impossible, to put into practice within the current time restraints in the NHS. Ideally, out-patient appointments with an interpreter should be twice as long as usual, and time should be given before and after the interview to talk to the interpreter, but where will the time come from?

There are two important omissions from the book. First, the editors were unable to find anyone to write about working with deaf patients, and signing interpreters. Although much of the book would apply to signing interpreters, it is an area that would have benefited from its own chapter. Second, the use of psychometric tests across languages and the interpretation of assessment instruments are not included.

Do you really need to read a 250-page book to learn how to work with interpreters? Probably not, but there is much of interest in this book and hopefully it will draw attention to this important area of practice, encourage more skills-based teaching and prompt someone to include it in the MRCPsych examinations.

Michael Phelan Consultant Psychiatrist, Charing Cross Hospital, London

\section{Clinical Effectiveness in Psychotherapy and Mental Health: Strategies and Resources for the Effective Clinical Governance}

McPherson, S., Richardson, P. \& Leroux, P. (eds)

London: Karnac, 2003, £16.99 pb, 154 pp., ISBN: 1-85575-902-0

On reviewing this book, I had two things in mind. First, what's new in the material presented? And second, is the material presented likely to be effective in helping change my clinical practice?

Some chapters were particularly impressive. The chapter on political milestones gave a very good overview of the evolution of a quality agenda in menta health. Other chapters in the early part of the book seemed full of 'management speak' and did not sustain my interest. The chapter entitled 'In defence of NHS Psychotherapy' by Phil Richardson and 


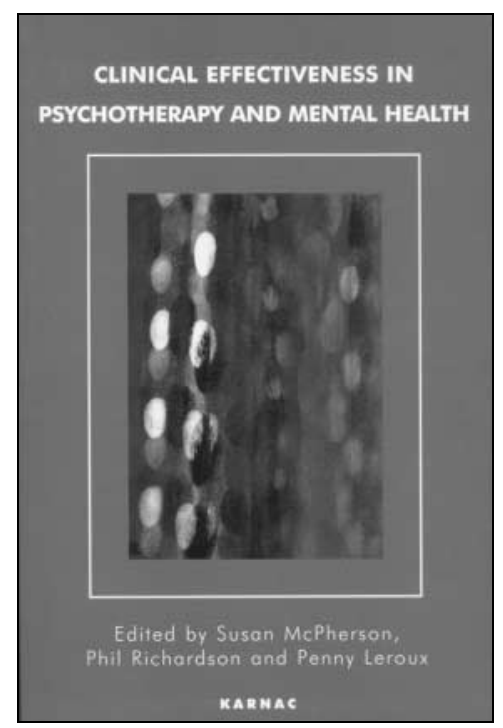

Peter Hobson was published previously in Psychoanalytic Psychotherapy. It presents a good case for the services provided at the Tavistock. There is little evidence of Tavistock NHS psychotherapy wishing to learn from current research so that clinical practice may be improved, and the planning, organisation and delivery of psychological therapy services made more effective. Chapter seven emphasises that 'it is no longer a disorder that is being treated but a person'. Phil Richardson here presents a good overview of evidencebased practice and the psychodynamic psychotherapies. However, this chapter seems rather discouraging and dispiriting for an individual attempting to base practice on evidence. Such an individual might well wish for guidance on a range of solutions, rather than just reading about the complexities and problems inherent in much evidence-based practice.

In their useful overview of the audit cycle, McPherson and Richardson recognise that the most difficult part of the audit cycle is in implementing change. I believe the attempts to distinguish between audit and research in chapters nine and ten create confusion and are not helpful. In the later chapters, complexities and problems are raised in the choice of outcome measures. The writers do not write as if the measures have been incorporated into the everyday evaluation of Tavistock Clinical Services. The examples given come from services outside the Tavistock Clinic, such as the Brandon Centre. I was disappointed that health service users seemed to be mentioned as a two-page afterthought in chapter fifteen. Clinical effectiveness in psychotherapy and mental health services might be greatly increased by the thoughtful involvement of health service users in the planning, organisation, development and delivery of psychological therapy services at the Tavistock and elsewhere.
I hope the next book on clinical effectiveness will be more forward-looking and will present a clearer vision of how things can move on in evaluating the psychological therapies, and with the Tavistock Clinic at the forefront of developments.

Kevin Healy Consultant Psychiatrist in Psychotherapy, Clinical Director, Cassel Hospital

\section{Cognitive BehaviourTherapy for People with Cancer}

Moorey, S. \& Greer, S. Oxford: Oxford University Press, 2002, f24.95 pb, 208 pp., ISBN: 0-19-850866-2

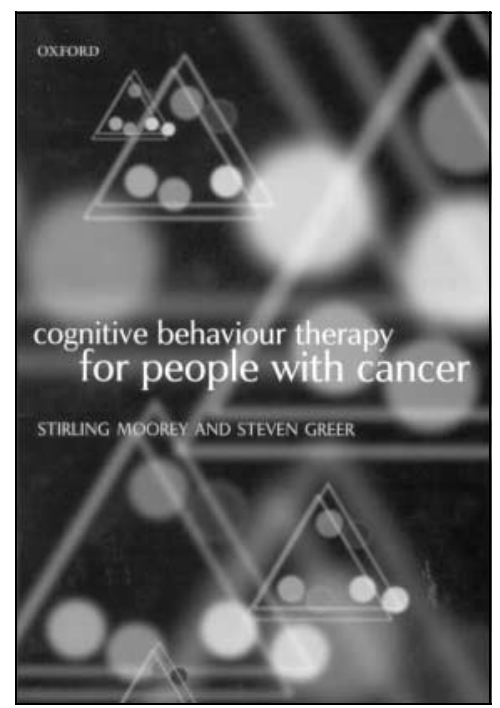

Psycho-oncology is a rapidly growing subspeciality, and this book should be an extremely useful aid to those involved in, or connected to, the subject. It is described in the foreword as a new edition of a previous book, Psychological Therapy for Patients with Cancer: A New Approach (Moorey \& Greer, 1989), but it has been substantially rewritten and updated.

Within the covers of a commendably short book the authors provide: a concise account of cognitive theory; an overview of the current evidence base of psychooncology; a description of the adaptation of CBT (cognitive-behavioural therapy), termed APT (adjuvant psychological therapy), for people with cancer, and practical descriptions of the application of APT in a variety of situations. The information is presented clearly, and is a pleasure to read.

Much of the material in the book will be familiar to experienced CBT therapists, who may feel that detail is either lacking or superficial. On the other hand, oncologists and other professionals working in oncology may well feel that it is too specialised to be of use to them. My main concern is therefore: does the book fall between two stools? Hopefully not: this is a handy text that should prove useful to a variety of professionals. Oncology nurse specialists, liaison nurses, liaison psychiatrists, health psychologists, and CBT therapists who only occasionally work with people with cancer are just some of the groups who may benefit from this book. Anyone negotiating with service commissioners may also find it a handy reference.

The techniques described in the book are mostly equally applicable to people with other serious, chronic or terminal physical illnesses, but this is not a point made in the book. Inadvertently, therefore, the book could be seen as giving the message that psychological responses to cancer, and subsequent therapeutic interventions, are somehow peculiar to cancer. It would be unfortunate if this book reinforced such a misapprehension, already prevalent among some colleagues in medicine.

Paul Gill Consultant in Liaison Psychiatry, Sheffield

\section{Family Work for Schizophrenia: A Practical Guide, second edition}

Kuipers, E., Leff, J. \& Lam, D. Gaskell, 2002, f15 pb, 152 pp., ISBN: 1-901242-77-3

There is ample evidence going back more than a decade that working with the families of people with schizophrenia reduces the rate of relapse significantly, yet in practice this rarely happens. This book, written by the most prominent researchers in this field, could help change that. It offers strategies, as well as describing issues and concerns that need to be kept in mind while working with these families.

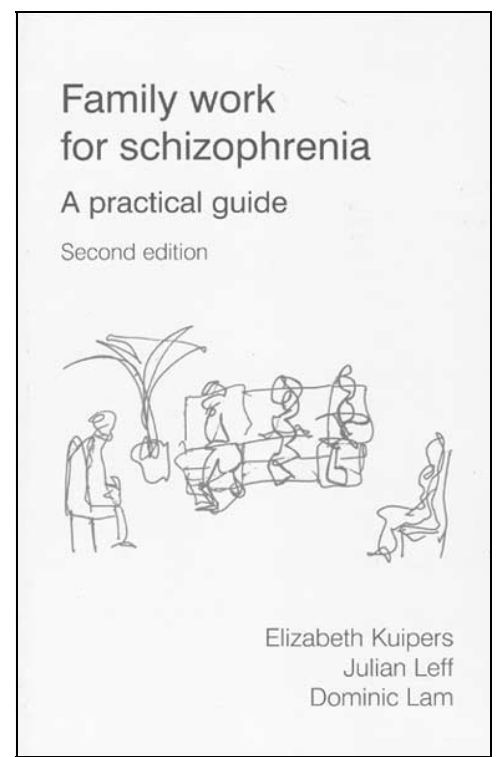

